Société d'histoire de la révolution de 1848 et des révolutions du XIXe siècle

$37 \mid 2008$

L'ère victorienne revisitée

\title{
Catherine NESCI, Le flâneur et les flâneuses. Les femmes et la ville à l'époque romantique
}

\section{Benoît Lenoble.}

\section{OpenEdition}

\section{Journals}

Édition électronique

URL : http://journals.openedition.org/rh19/3543

DOI : $10.4000 /$ rh 19.3543

ISSN : $1777-5329$

Éditeur

La Société de 1848

Édition imprimée

Date de publication : 15 novembre 2008

Pagination : 185-242

ISSN : 1265-1354

Référence électronique

Benoît Lenoble., « Catherine NESCl, Le flâneur et les flâneuses. Les femmes et la ville à l'époque romantique », Revue d'histoire du XIXe siècle [En ligne], 37| 2008, mis en ligne le 01 décembre 2008 , consulté le 22 septembre 2020. URL : http://journals.openedition.org/rh19/3543 ; DOI : https:// doi.org/10.4000/rh19.3543

Ce document a été généré automatiquement le 22 septembre 2020

Tous droits réservés 


\title{
Catherine NESCI, Le flâneur et les flâneuses. Les femmes et la ville à l'époque romantique
}

\author{
Benoît Lenoble.
}

\section{RÉFÉRENCE}

Catherine NESCI, Le flâneur et les flâneuses. Les femmes et la ville à l'époque

romantique, Grenoble, ELLUG, Bibliothèque stendhalienne et romantique, 2007, $440 \mathrm{p}$.

ISBN : 978-2-84310-105-2. 32 euros.

1 Rendre compte d'une recherche dont on connaitt, avant même la publication, les approches et les contenus en affecte la perception. L'auteure était déjà une spécialiste de la littérature et des écrivaines françaises du XIX siècle quand, à la suite d'une invitation, elle dirigea un séminaire de maîtrise consacré aux Parisiennes de 1830 à 1880 pendant une année à l'université Paris VII. L'étudiant que j'étais se souvient de l'enthousiasme, de la précision et de la finesse que manifestait Catherine Nesci pour ses objets de recherche et qu'elle continue à exprimer dans cet ouvrage. Ce dernier est une enquête aboutie, presque un essai, sur les relations entre les femmes et la ville dans la représentation romantique, notamment dans la culture moderne de la flânerie, source de fantasmagories et de phénoménologies contemporaines. "Archéologie sexuée de la modernité littéraire et esthétique " (p. 19), il vise à montrer comment les femmes de lettres ont écrit et fait progresser, durant le premier XIX ${ }^{e}$ siècle, les représentations de la féminité en ville à travers leurs expériences du milieu urbain et, surtout, de la flânerie. Car, contrairement à ce que l'on pensait, la flâneuse existe. Elle s'est construite et singularisée contre le modèle du flâneur balzacien, qui ravale la femme au rang d'objet et de décor citadins. Elle a investi et s'est appropriée lentement l'espace public dans l'imaginaire de la littérature moderne. C'est ce que démontre l'auteure en se livrant à une analyse littéraire et culturelle, secondairement sociologique et historique, de plusieurs écrits d'hommes et, en grande partie, de femmes. Matières ici premières, 
l'écriture et l'intertexte sont décortiqués, décryptés et commentés dans toute leur complexité avec subtilité et rigueur. Ils sont parfois croisés avec quelques documents iconographiques bien choisis.

2 Très spécialisée, la démarche est intéressante mais pas toujours évidente à suivre. Faisant référence à des œuvres allant de la fin de l'Ancien Régime à la décennie 1840, l'exposé est centré sur le romantisme. Il s'appuie sur un appareillage développé de notes de bas de page et une dense bibliographie. Structuré en cinq parties et dix chapitres, il part d'une relecture de la flânerie et du flâneur, puis la confronte aux productions, successivement, d'Honoré de Balzac, de Delphine Gay, d'Aurore Dupin et de Flora Tristan. Afin de cerner, chez chaque auteur, leur conception de la flânerie et leurs expériences évolutives de la modernité urbaine, Catherine Nesci se focalise sur leurs textes les plus révélateurs. Si les études par plume sont convaincantes et si une progression par paliers se dégage clairement, leur articulation générale manque de solidité dans la mesure où les liens ou influences entre les auteurs ne sont pas toujours reconstitués. Cette discontinuité n'empêche pas d'apprécier le panorama des mises en relation littéraires de la femme et de la ville.

Dans ce paysage de lettres et d'écrits, trois perspectives se fondent en permanence et contribuent à inscrire différemment la flâneuse dans la cité. Le travestissement en est la première. Face à l'identification sociale et à l'érotisation symbolique des femmes dans la littérature balzacienne, les plumes féminines imaginent diverses formes de camouflage, fictives ou réelles, pour dissimuler la femme et rendre possible son observation et sa mobilité propres : Delphine de Girardin rédigeant son feuilleton dans La Presse sous le pseudonyme de vicomte de Launay, George Sand qui découvre Paris habillée en homme d'après son récit autobiographique, la paria Flora Tristan transfigurée par les épreuves qu'elle s'inflige et porteuse de la saya (habit féminin typique au Pérou) pour enquêter dans Lima. Ainsi prend forme et consistance la flâneuse qui se joue des regards masculin et collectif. Sans ces déguisements et subterfuges ingénieux que Catherine Nesci dévoile les uns après les autres, la femme et le féminin autonomes ne seraient pas entrés dans l'imaginaire urbain. Constituant la seconde dimension, la satire, la mascarade et le carnavalesque sont des procédés communs destinés à démonter et recomposer efficacement les représentations dominantes. Dans Le Lorgnon et La Canne de M. de Balzac, Delphine de Girardin parodie l'empereur du roman, mélange les genres et invente un style plein d'humour et d'excentricité à l'ironie moralisatrice. Dans Horace, George Sand déploie une image critique de l'espace public urbain en supprimant les aspects érotique et voyeur de la grisette, en métamorphosant cette dernière en femme artiste bohème. Dans les Pérégrinations d'une paria, avec virulence et sensibilité, Flora Tristan dénonce la vision littéraire de Paris et des Parisiens par le prisme des témoignages qu'elle rapporte et des jugements qu'elle produit sur la ville depuis la capitale péruvienne. Cette perspective est la mieux exposée et expliquée par l'auteure, au détriment, peut-être, de celle de la visibilité et de la publicité concrètes de la femme dans la ville et l'espace public. Certes, Delphine de Girardin met en scène l'actualité et les mœurs urbaines en parlant chiffons, et par extension des femmes, mais cela se fait vraisemblablement aussi par la fréquentation physique des salons et de la bonne société. De même, George Sand reconfigure la représentation culturelle de la ville par le récit de ses déambulations, probablement également par des anecdotes, scènes et tranches de vie emblématiques de ses expériences et qui ne paraissent pas prises en compte ici. De la même manière, 
rappeler le cheminement géographique de Flora Tristan aurait renforcé l'analyse littéraire de ses textes et enquêtes. Fortement subjectif, ce défaut de description et de réalisme n'altère pas la qualité de ce travail qui comble une lacune dans les études romantiques françaises, qui fait émerger une autre modernité et prendre conscience du caractère sexué de l'histoire. 